\title{
CLINICAL, MAMMOGRAPHIC AND ULTRASONOGRAPHIC EVALUATION OF RESIDUAL DISEASE IN WOMEN RECEIVING NEOADJUVANT CHEMOTHERAPY FOR LOCALLY ADVANCED BREAST CANCER
}

\author{
Amit Agrawal', Gambheer Singh², Manju Singh ${ }^{3}$ \\ ${ }^{1}$ Assistant Professor, Department of Surgery, Pt. JNM Medical College, Raipur. \\ 2 Professor and HOD, Department of Surgery, RIMS, Raipur. \\ ${ }^{3}$ Professor, Department of Surgery, Pt. JNM Medical College, Raipur.
}

\begin{abstract}
\section{BACKGROUND}

Locally advanced breast cancer (LABC) defined as bulky primary tumour with T3, T4 tumour and N2/N3 disease. Neoadjuvant chemotherapy is the first-line treatment to downgrade these tumours and to make them surgically operable and also better cosmesis. Chemotherapy response is assessed by various methods.

Aim of our study was to assess the residual disease clinically, mammographically and sonographically.
\end{abstract}

\section{MATERIALS AND METHODS}

Residual disease was compared with histopathological response after 4 cycles of chemotherapy followed by classical surgery Modified Radical Mastectomy.

\section{RESULTS}

In our institute, more than $60 \%$ of women with breast cancer present with locally advanced disease and are submitted for neoadjuvant chemotherapy. Total 60 cases of LABC were included in this study, 42 patients were of T4bN1M0 stage, 12 were of T3N1M0 stage, 3 were T3N2M0 and 3 were T4bN2M0 stage. Response assessed by RECIST criteria. Pre-chemotherapy mean value of clinical size of tumour was $6.3 \mathrm{~cm}$ and post-chemotherapy mean value was $5.2 \mathrm{~cm}$. Mammographically, pre-chemotherapy mean size was $4.23 \mathrm{~cm}$ and post-chemotherapy $3.8 \mathrm{~cm}$. In USG pre-chemotherapy mean size was $4.56 \mathrm{~cm}$ and post-chemotherapy 3.74 $\mathrm{cm}$. Three patients showed Complete Response (CR) on USG evaluation but none clinically or mammographically. The mean size of tumour was $35 \%$ larger on clinical examination as compared to mean size on pathological evaluation. Mammographically tumour size was $8 \%$ underestimated and sonographically $4 \%$ underestimated than pathological tumour size which is statically significant with $\mathrm{p}$ value $<0.05$.

\section{CONCLUSION}

Ultrasonography is superior to clinical and mammographic assessment of residual tumour after neoadjuvant chemotherapy in LABC.

\section{KEYWORDS}

Locally Advanced Breast Cancer, Neoadjuvant Chemotherapy, Residual Disease, LABC.

HOW TO CITE THIS ARTICLE: Agrawal A, Singh G, Singh M. Clinical, mammographic and ultrasonographic evaluation of residual disease in women receiving neoadjuvant chemotherapy for locally advanced breast cancer. J. Evolution Med. Dent. Sci. 2017;6(3): 207-209, DOI: $10.14260 /$ Jemds/2017/48

\section{BACKGROUND}

Locally advanced breast cancer (LABC) is defined as bulky primary tumour and or extensive lymphadenopathy. This includes patients of T3 \& T4 disease with/or N2/N3 disease. Breast cancer is one of the leading causes of cancer related deaths in women. Its mortality/incidence relationship in developed countries is $29.9 \%$ whereas in developing countries it reaches $42.9 \%$. [1]

The treatment of LABC has considerably changed during last decade and now includes a multidisciplinary approach which is directed both to locoregional control of disease and to destruction of micrometastases.[2-3] Neoadjuvant chemotherapy may improve the survival rate, enable direct

Financial or Other, Competing Interest: None.

Submission 04-12-2016, Peer Review 08-12-2016,

Acceptance 03-01-2017, Published 09-01-2017.

Corresponding Author:

Dr. Amit Agrawal,

HIG C/72 Shailendra Nagar,

Raipur-492001,

Chhattisgarh.

E-mail: doc.amitagrawal@gmail.com

DOI: $10.14260 /$ jemds $/ 2017 / 48$

assessment of response to systemic treatment and causes a reduction in size of primary tumour, allowing a more conservative surgical approach without any increase in locoregional recurrence rate.[4-5] $0 \mathrm{n}$ the other hand the theoretical disadvantage related to chemotherapy is-

1. Potential delay of surgical treatment particularly where active neoplastic proliferation is detected after four cycles of chemotherapy.

2. Loss of knowledge and information about some prognostic factors such as clinical nodal status and size of tumour which may lead to suboptimal therapy.

3. Modification of biological temporal characteristic as change in cell proliferation.[6]

Assessment of response to neoadjuvant chemotherapy has slowed down the development of new protocols for breast carcinoma. Clinical, radiological along with pathological evaluation is important to assess proper response.[7] In our study, total 60 patients of LABC were studied clinically, mammographically and sonographically prior to and after 4 cycles of chemotherapy. We compared the response by these three methods. 


\section{Aim and Objectives}

To evaluate the residual disease in LABC after 4 cycles of chemotherapy clinically, mammographically, sonographically and comparing with tumour size pathologically postoperatively.

\section{MATERIALS AND METHODS}

Present prospective observational study was conducted in Department of Surgery, Pt. JNM Medical College, Raipur, Chhattisgarh. All female patients diagnosed of LABC undergoing neoadjuvant chemotherapy were included in this study. Total 60 patients were assessed by clinical examination, mammographic evaluation and sonographic evaluation (done before core biopsy was taken), then chemotherapy was started.

Clinical assessment was done by TNM classification and repeated after 4 cycles of neoadjuvant chemotherapy and the response was assessed with RECIST criteria.[8]

Film screen mammography was done on MAMMOMAT 3000 Nova machine with standard protocol and response assessed with same criteria.

Sonologic evaluation was done in Department of Radiology under supervision of a qualified sonologist of preand post-chemotherapy and response assessed.

\section{RESULTS}

The peak incidence of the cases was seen in patients below 35 years of age ( $41.66 \%$ ) while mean age was 42.08 years. LABC was found more in left breast that is 36 out of 60 cases $(60 \%)$ and 42 out of 60 patients were premenopausal females (70\%). Clinically, 42 out of 60 patients presented with T4bN1M0. Stage wise distribution of patients shown in Table -1

\begin{tabular}{|c|c|c|}
\hline Stage & No. of Cases & Percentage \\
\hline T3N1M0 & 12 & $20 \%$ \\
\hline T3N2M0 & 03 & $5 \%$ \\
\hline T4bN1M0 & 42 & $70 \%$ \\
\hline T4bN2M0 & 03 & $5 \%$ \\
\hline \multicolumn{2}{|c|}{ Table 1. Clinical Stage Wise Distribution } \\
\hline
\end{tabular}

Pre-chemotherapy mean clinical size of lump with standard deviation (SD) was $6.3 \pm 1.4 . \mathrm{cm}$. Post-chemotherapy mean clinical size with SD was $5.2 \pm 1.9 \mathrm{~cm}$. The difference was statistically significant with $\mathrm{p}$ value $<0.001$. Mean value of mammographic size was $4.2 \pm 1.5 \mathrm{~cm}$ pre-chemotherapy and $3.6 \pm 1.8 \mathrm{~cm}$ post-chemotherapy. The difference was statistically significant with $\mathrm{p}$ value $<0.01$.

Ultrasonography mean value of tumour size was $4.5 \pm 1.06$ $\mathrm{cm}$ before chemotherapy and $3.74 \pm 1.64 \mathrm{~cm}$ postchemotherapy. The difference was statistically significant with $\mathrm{p}$ value $<0.01$.

Response to chemotherapy is shown in Table 2, 3, with RECIST criteria.

\begin{tabular}{|c|c|}
\hline $\begin{array}{c}\text { Best } \\
\text { Response }\end{array}$ & RECIST change in sum longest diameter \\
\hline $\begin{array}{l}\text { Complete } \\
\text { response } \\
\text { (CR) }\end{array}$ & $\begin{array}{l}\text { Disappearance of all target lesions; confirmed } \\
\text { at } 4 \text { weeks }\end{array}$ \\
\hline $\begin{array}{l}\text { Partial } \\
\text { Response } \\
\quad(\mathrm{PR})\end{array}$ & $\begin{array}{c}\text { At least 30\% reduction in the sum of the } \\
\text { longest diameter of target lesion, taking as } \\
\text { reference the baseline study; confirmed at } 4 \\
\text { weeks }\end{array}$ \\
\hline $\begin{array}{c}\text { Stable } \\
\text { Disease ( SD) }\end{array}$ & $\begin{array}{l}\text { Neither PR or PD criteria are met, taking as } \\
\text { reference the smallest sum of the longest } \\
\text { diameter recorded since treatment started }\end{array}$ \\
\hline $\begin{array}{l}\text { Progressive } \\
\text { Disease (PD) }\end{array}$ & $\begin{array}{l}\text { At least } 20 \% \text { increase in the sum of the longest } \\
\text { diameter of target lesion, taking as reference, } \\
\text { the smallest sum of longest diameter recorded } \\
\text { since treatment started or appearance of new } \\
\text { lesion. }\end{array}$ \\
\hline \multicolumn{2}{|c|}{$\begin{array}{c}\text { Table 2. RECIST Criteria of Evaluation of Response to } \\
\text { Chemotherapy }\end{array}$} \\
\hline
\end{tabular}

\begin{tabular}{|c|c|c|c|c|c|c|}
\hline \multirow{2}{*}{ Response } & \multicolumn{2}{|c|}{ Clinical } & \multicolumn{2}{c|}{ Mammography } & \multicolumn{2}{c|}{ Sonography } \\
\cline { 2 - 7 } & $\begin{array}{c}\text { No. of } \\
\text { Cases }\end{array}$ & $\%$ & $\begin{array}{c}\text { No. of } \\
\text { Cases }\end{array}$ & $\%$ & $\begin{array}{c}\text { No. of } \\
\text { Cases }\end{array}$ & $\%$ \\
\hline CR & 0 & $0 \%$ & 0 & $0 \%$ & 3 & $5 \%$ \\
\hline PR & 24 & $40 \%$ & 18 & $30 \%$ & 18 & $30 \%$ \\
\hline SD & 33 & $55 \%$ & 36 & $60 \%$ & 36 & $60 \%$ \\
\hline PD & 3 & $5 \%$ & 6 & $10 \%$ & 3 & $5 \%$ \\
\hline Table 3. Response Evaluations on Clinical, Mammography \\
and Sonography Method after Neoadjuvant Chemotherapy \\
\hline
\end{tabular}

This study showed no complete response as assessed by clinical and mammography methods, but in USG complete response was present in 3 patients. All responses were confirmed by pathological assessment of tumour size. The mean size of tumour was 35\% underestimated (Larger) on clinical assessment as compared to mean size on pathological examination. The mean size of tumour was $8 \%$ underestimated by mammography and $4 \%$ underestimated by sonography than pathological assessment which was statistically significant with $\mathrm{p}$ value $<0.05$.

\section{DISCUSSION}

Breast cancers in young women are typically aggressive in part owing to the overexpression of high grade, triple negative disease. Average age of presentation for LABC is 4045 years in various studies.[9-10] Our findings are in conformity with the reported range.

In our series, about $60 \%$ had left-sided LABC and $40 \%$ had right-sided LABC. Possible reasons for left preponderance of carcinoma are highly speculative, sleeping behaviour, handedness, nursing behaviour and asymmetric sun exposure.[11] Clemmensen (1997) found left breast preponderance in 18\% LABC,[12] Haagensen (1995) in 16.5\% and Donegen (1997) in 26\% cases of LABC.[13] Our finding of $20 \%$ preponderance in left-sided LABC is in accordance with reports. LABC are aggressive tumour due to ER/PR negativity and HER-2/neu overexpression so commonly seen in premenopausal women.[14] This study also showed peak incidence in premenopausal women.

Definition of LABC includes palpable axillary lymph nodes. Olivotto IA (2003) defined LABC as patients with T3 or 
T4 and N2/N3 disease.[15] In our study, also all patients were of palpable axillary lymph node with $\mathrm{N} 1$ and N2 stage.

All patients received 4 cycles of chemotherapy as per standard protocol and after 4 cycles response was assessed by RECIST criteria.[8] USG appears superior to clinical examination and mammography in assessment of postchemotherapy tumour response. Physical examination is often considered unsatisfactory for assessment of response because palpation of fibrotic and necrotic mass may mimic residual tumour mass.[16-17] Ultrasonography is a superior imaging modality than mammography in evaluating skin thickening and oedema and for evaluating axillary lymphadenopathy. Different researchers reported sensitivity $72-94 \%$ and specificity up to $97 \%{ }^{[18]}$ for USG. In our study, also USG assessment of tumour response appears superior compared to clinical and mammographic assessment. In current era, MRI appears to be superior to all for this evaluation in cases of multifocal or multicentric disease. MR data improves accuracy of the second look ultrasound with an increase of ultrasound accuracy from $73-84.5 \%{ }^{[19]}$

\section{CONCLUSION}

LABC is an aggressive form of carcinoma breast; proper response assessment to neoadjuvant chemotherapy is required for better prognostic and cosmetic surgical management of these tumours. USG is a feasible method of noninvasive evaluation of response to chemotherapy in patients with locally advanced breast cancer as compared to physical examination and mammographic evaluation and also where facilities of MRI are not available.

\section{REFERENCES}

[1] Parkin DM, Bray F, Pisani P, et al. Estimating the world cancer burden: Globocan 2000. Intl J Cancer 2001;94(2):153-6.

[2] Fisher B, Brown A, Mamounas E, et al. Effect of preoperative chemotherapy on local-regional disease in women with operable breast cancer: findings from national surgical adjuvant breast and bowel project B18. J Clin Oncol 1997;15(7):2483-93.

[3] Abraham DC, Jones RC, Jones SE, et al. Evaluation of neoadjuvant chemotherapeutic response of locally advanced breast cancer by magnetic resonance imaging. Cancer 1996;78(1):91-100.

[4] Dash N, Chafin SH, Johnson RR, et al. Usefulness of tumour marker clip in patient in undergoing neoadjuvant chemotherapy for breast cancer. Am J Roentgenol 1999;173(4):911-7.

[5] Vinicombe SJ, MacVicar AD, Guy RL, et al. Primary breast cancer: mammographic changes after neoadjuvant chemotherapy, with pathologic correlation. Radiology 1996;198(2):333-40.
[6] Fisher B, Mamounas EP. Preoperative chemotherapy: a model for studying the biology and therapy of primary breast cancer. J Clin Oncol 1995;13(3):537-40.

[7] Trecate G, Ceglia E, Stabile F, et al. Tumori della mammella localmente avanzati: ruolo della RMN nella valutazione della risposta alla terapia prechirurgica e del residuo neoplastico prima dell'intervento. Radiol med 1998;95:449-55.

[8] Therasse P, Arbuck SG, Eisenhauer EA, et al. New guidelines to evaluate the response to treatment in solid tumours. J Natl Cancer Inst 2004;96(6):487-8.

[9] Tyagi SP, Khan MS. Carcinoma of breast: its incidence and histomorphological variant in Aligarh. Indian Jr of surgery 1990.

[10] Badwe RA, Mitra S. Clinicopathological features and prognosis of breast cancer in India. Indian Jr of India 1990.

[11] Wilting J, Hagedorn M. Left-right asymmetry in embryonic development and breast cancer: common molecular determinants. Curr Med Chem 2011;18(36):5519-27.

[12] Clemmenson J. Stastistical studies in the etiology of neoplasm. Review and results 1997.

[13] Donegen W. Staging and end results. In: Cancer of the breast. Spratt J, Donegen W, (eds). Philadelphia WB, Saunders 1997.

[14] Smithers DW. Cancer of breast. $\mathrm{Br} \mathrm{Jr}$ Radiology 1952;4(1).

[15] Olivotto IA, Chua B, Allen SJ, et al. Long-term survival of patients with supraclavicular metastasis at diagnosis of breast cancer. J Oncol 2003;21(5):851-4.

[16] Feldman LD, Hortobagyi GN, Buzdar AU, et al. Pathological assessment response to induction chemotherapy in breast cancer. Cancer Res 1986;46(5):2578-81.

[17] Cocconi G, Di Blasio B, Alberti G, et al. Problems in evaluating response of primary breast cancer to systemic therapy. Breast cancer Res Treat 1984;4(4):309-13.

[18] Walsh R, Kornguth PJ, Soo MS, et al. Axillary lymph node: mammographic, pathological, and clinical correlation. AJR Am J Roentgenol 1997;168(1):33-8.

[19] Londero V, Bazzocchi M, Farte DC, et al. Locally advanced breast cancer: comparison of mammography, sonography, and MR imaging evaluation of residual disease in women receiving neoadjuvant chemotherapy. Eur Radiology 2004;14(8):1371-9. 